\title{
Exergetic Analysis of Cogeneration Energy Sources
}

\author{
Dmitriy R. Bibikov, \\ Anton K. Poley and Alexander V. Kulik* \\ Far Eastern Federal University \\ Vladivostok, Russian Federation
}

Received 26.03.2020, received in revised form 17.04.2020, accepted 21.05.2020

\begin{abstract}
This article discusses the method of thermal and exergetic analysis of cogeneration energy sources on the example of the gas turbine unit LM6000PF (GTU-CHPP «Vostochnaya»). The purpose of the conducted exergetic analysis is to determine the most advantageous method for evaluating the performance of equipment in terms of thermodynamic efficiency. The comparison of GTU efficiency values obtained by calculation using the methods of thermal and exergetic analysis is performed. A special feature of the exergetic analysis is the use of an additional indicator as exergy along with energy indicator. In the analysis, the efficiency of using the energy of the fuel burned in the GTU combustion chamber and the working bodies of the gas cycle for the production of electrical and thermal energy is assessed by comparing the actually accomplished work with the exergy of the process.
\end{abstract}

Keywords: gas turbine unit, cogeneration, energy analysis, energy efficiency.

\section{Эксергетический анализ}

\section{когенерационных энергоисточников}

\author{
Д.Р. Бибиков, А.К. Полей, А.В. Кулик \\ Дальневосточный федеральный университет \\ Российская Федерачия, Владивосток
}

Аннотация. В данной статье рассмотрен метод теплового и эксергетического анализа работы когенерационных энергоисточников на примере газотурбинной установки LM6000PF (ГTУТЭЦ «Восточная»). Целью проведенного эксергетического анализа служит определение наиболее выгодного с точки зрения термодинамической эффективности способа оценки работы оборудования. Выполнено сравнение величин КПД ГТУ, полученных расчетным путем по

(C) Siberian Federal University. All rights reserved

This work is licensed under a Creative Commons Attribution-Non Commercial 4.0 International License (CC BY-NC 4.0).

* Corresponding author E-mail address: bibikov_dr@dvfu.ru, anton.poley@gmail.com,kulik_av@dvfu.ru 
методикам теплового и эксергетического анализа. Особенностью проведения эксергетического анализа является использование помимо энергии дополнительного показателя - эксергии. В ходе проведения эксергетического анализа оценивается эффективность использования энергии сжигаемого в камере сгорания ГТУ топлива и рабочих тел газового цикла для производства электрической и тепловой энергии путем сравнения фактически совершенной работы с эксергией процесса.

Ключевые слова: газотурбинная установка, когенерация, энергетический анализ, энергоэффективность.

Цитирование: Бибиков, Д.Р. Эксергетический анализ когенерационных энергоисточников / Д.Р. Бибиков, А.К. Полей, А.В. Кулик // Журн. Сиб. федер. ун-та. Техника и технологии, 2020. 13(6). С. 690-701. DOI: 10.17516/1999-494X-0257

\section{Введение}

Вопросы энергосбережения в нашей стране в связи с удорожанием всех видов топлива становятся чрезвычайно актуальными. Чтобы определить, где и в каком количестве можно уменьшить расход топлива, теплоты или электроэнергии, необходимо проводить тщательный анализ совершенства энергоиспользования на каждом энергетическом предприятии и в каждом его технологическом процессе. Существует прямая связь между уровнем анализа экономичности и достигнутыми технико-экономическими показателями тепловых электростанций. Исследование совершенства различных теплоиспользующих установок до настоящего времени проводится, как правило, посредством составления тепловых балансов, основанных на первом законе термодинамики - законе сохранения и превращения энергии, включающем в себя принцип эквивалентности различных видов энергии [1].

При составлении энергетических балансов тепловых электростанций и проведении их сопоставления все виды энергии выражают в эквивалентных энергетических величинах. Роль эквивалента выполняет энергия как количественная мера различных движений материи, а виды энергии, входящие в энергетический баланс, выражаются в Дж, ккал или кВт*ч.

Развитие теплоэнергетики привело к такому усложнению тепловых схем, что их анализ с использованием только энергетических балансов стал недостаточным. Так, на тепловой электростанции в процессах преобразования исходной энергии топлива в электроэнергию участвуют такие виды энергии, как химическая энергия топлива, энергия потока тепла, энергия потока пара, механическая энергия и электрическая энергия, ценность которых с точки зрения возможности их практического использования различна.

Налагаемое вторым законом термодинамики ограничение на превратимость теплоты в работу позволяет во всех теплоэнергетических установках дополнительно составить баланс работоспособной энергии (эксергетический баланс) [2].

Поскольку энергетические процессы в любой термодинамической системе протекают в окружающей среде, параметры которой практически остаются неизменными, то, используя второе начало термодинамики, всегда можно определить максимальное количество работы, которое может быть полезно при данных условиях любым энергетическим потоком, и тем самым оценить его работоспособную часть, названную эксергией.

Эксергия - это максимальное количество работы, которое может быть получено при переходе термодинамической системы обратимым путем в состояние равновесия с окружающей средой. Этот термин ввел в термодинамику в 1955 г. югославский ученый зоран Рант, 
чтобы разделить энергию на работоспособную и неработоспособную (анергию) части. Эксергия - это максимальное количество работы, которое может быть получено при переходе термодинамической системы обратимым путем в состояние равновесия с окружающей средой.

Эксергия характеризует энергию любого вида не только по ее количеству; она дает возможность количественно оценить и качественную ее сторону, т. е. она представляет собой некоторую универсальную меру энергетических ресурсов.

В связи с тем, что действительная выработка механической или электрической энергии в теплоэнергетической установке прямо пропорциональна использованной работоспособности, эксергетический баланс позволяет выявить не только очаги потерь, но и степень влияния каждой потери на общую выработку энергии и расход топлива. Эксергетический баланс, при сравнении его с тепловым, дает возможность рационально оценить параметры отдельных потоков циркулирующего рабочего тела, а также дать оценку распределению потерь в отдельных звеньях тепловой электростанции.

Увеличение доли газотурбинных установок (в балансе производства электрической энергии РФ), работающих в режиме когенерации, создает необходимость выявления различных подходов в определении энергоэффективности и учета потерь энергии. Суммарные затраты топлива при комбинированной выработке электрической и тепловой энергии (когенерации) значительно ниже, чем при их раздельном производстве, но просто вычленить расходы топлива на каждый вид продукции невозможно. В настоящее время Министерством энергетики РФ для распределения затрат топлива ГТУ рекомендован пропорциональный метод распределения затрат, но это не означает, что другие способы не могут применяться на ТЭЦ, в том числе для определения анализа работы ГТУ и повышения энергоэффективности установок [3].

\section{Эксергетический и тепловой расчет ГTУ LM}

Эксергетический анализ работы ГТУ направлен на определение степени термодинамического совершенства получения полезной работы в ГТУ простого газового цикла с учетом различных температур наружного воздуха из диапазона минус $30 \ldots 30{ }^{\circ} \mathrm{C}$.

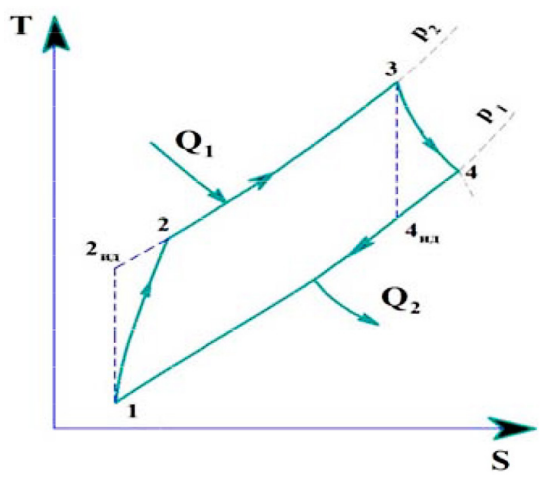

Рис. 1. Цикл Брайтона ГТУ при отсутствии промежуточного охлаждения циклового воздуха

Fig. 1. GTU Brighton cycle in the absence of intermediate cooling of cyclic air 
На рис. 1 представлен простой цикл Брайтона газотурбинной установки (без использования промежуточного охлаждения сжимаемого циклового воздуха) [4] со следующими обозначениями процессов: 1-2 - сжатие воздуха в турбокомпрессоре ГТУ; 2-3 - подвод теплоты к циклу в камере сгорания ГТУ; 3-4 - расширение газов в турбине ГТУ; 4-1 - отвод теплоты из цикла.

Точка 1. Состоянию воздуха перед турбокомпрессором ГТУ соответствуют параметры окружающей среды: давление $-P_{l}=0,1$ МПа; температура $-t_{1}$, энтальпия $-h_{l}$, энтропия $-s_{l}$, специальная функция адиабатного процесса $-\pi_{1}$.

Точка 2(ид). Давление циклового воздуха после турбокомпрессора ГТУ определяется степенью повышения давления воздуха:

$$
p_{2=} p_{1} * \pi_{m \kappa} .
$$

Для нахождения свойств воздуха в конце обратимого (адиабатного) процесса сжатия (точка 2 ид) необходимо определить значение функции $\pi_{2}$.

$$
\pi_{m \kappa}=\pi_{1} * \frac{p_{2}}{p_{1}}
$$

По найденному значению $\pi 2$ определяются остальные свойства воздуха после адиабатного процесса сжатия в турбокомпрессоре ГТУ: температура $-t_{2}$ ид, энтальпия $-h_{2}$ ид энтропия $s_{2 u \partial}=s_{1}$.

Точка 2. Энтальпия воздуха в конце необратимого процесса сжатия в турбокомпрессоре ГТУ:

$$
h_{2}=h_{1}+\left[\left(h_{2 u \partial}-h_{1}\right) / \eta_{0 i}^{T K}\right],
$$

где $\eta_{0 i}^{T K}=0,88-$ КПД турокомпрессора.

По полученной величине энтальпии определяют значения температуры $t_{2}$ и энтропии $s_{2}$. Уточненное значение энтропии в конце реального процесса сжатия находим с учетом универсальной газовой постоянной $\mathrm{R}=0,287$ (кДж/кг $\cdot \mathrm{K})$ :

$$
s_{2}=\mathrm{s}_{2}^{\prime}-\left[R * \ln -\left(p_{2} / p_{1}\right)\right] .
$$

Точка 3. По начальной температуре газов $\left(\mathrm{t}_{3}=1250\right.$ - для General Electric LM6000PF) определяются параметры газов перед газовой турбиной: энтальпия $-h_{3}$, энтропия $-s_{3}^{0}$, функция $\pi_{3}$. Уточненное значение энтропии газов перед турбиной:

$$
s_{3}=\mathrm{s}_{3}^{0}-\left[R * \ln -\left(p_{2} / p_{1}\right)\right] .
$$

Точка 4(ид). Для определения термодинамических свойств газов после «идеального» процесса расширения в газовой турбине необходимо определить функцию адиабатного процесса $\pi 4:$

$$
\pi_{4}=\pi_{3} *\left(p_{1} / p_{2}\right)
$$

После этого определяют остальные свойства газов в данной точке: температура $-\mathrm{t}_{4}$, эн-

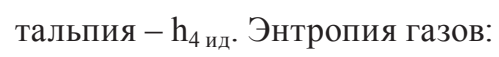

$$
s_{4 \text { ид }}=\mathrm{s}_{3} .
$$


Точка 4. Энтальпия газов в конце действительного процесса расширения в турбине определяется по формуле

$$
h_{4}=h_{3}-\left[\left(h_{3}-h_{4 u \partial}\right) / \eta_{0 i}^{\Gamma T}\right],
$$

где $\eta_{0 i}^{\Gamma T}=0,87-$ КПД газовой турбины.

По полученному значению энтальпии определяют температуру $t 4$ и энтропию $s 4$ газов в конце «реального» процесса расширения в турбине.

Определение термодинамических свойств рабочего тела ГТУ в характерных «точках» газотурбинного цикла позволяет вычислить удельную работу газовой турбины и турбокомпрессора ГТУ, а также термический и полный КПД газотурбинной установки. Значения удельной

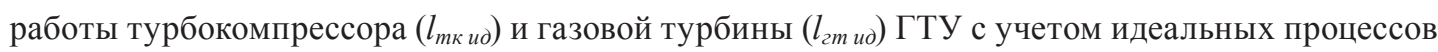
сжатия и расширения рабочего тела установки вычисляют через разницу энтальпий:

$$
\begin{aligned}
& l_{\text {ткид }}=h_{2 \text { ид }}-h_{1}, \\
& l_{\text {гтид }}=h_{3}-h_{4 и \partial} .
\end{aligned}
$$

Значения удельной работы турбокомпрессора $\left(l_{m \kappa}\right)$ и газовой турбины $\left(l_{m 2}\right)$ ГТУ с учетом необратимости процессов сжатия и расширения рабочего тела газотурбинного цикла:

$$
\begin{aligned}
& l_{\text {тк }}=h_{2}-h_{1}, \\
& l_{\text {гm }}=h_{3}-h_{4} .
\end{aligned}
$$

Термический КПД газотурбинного цикла характеризует степень совершенства ГТУ:

$$
\eta_{t}=\frac{l_{2 m}-l_{m \kappa}}{q_{1}}
$$

где $q_{1}=h_{3}-h_{2}-$ количество теплоты, подведенной в камеру сгорания ГТУ.

Общий КПД газотурбинной установки вычисляется по формуле

$$
\eta_{2 m y}=\frac{\left.l_{2 m} * \eta_{M}+l_{m \kappa}\right) * \eta_{\partial z}}{q_{1 * \eta_{k c}}}
$$

где $\eta_{к c}, \eta_{э г,} \eta_{м}-$ КПД камеры сгорания, электрогенератора, вала ГТУ.

На мощность ГТУ оказывают влияние значения удельной работы турбокомпрессора и газовой турбины ГТУ, а также объемные расходы циклового воздуха и нагретых до высокой температуры газов:

$$
N_{z m y}=\left[G_{2} *\left(h_{3}-h_{4}\right)\right]+\left[G_{6} *\left(h_{2}-h_{1}\right],\right.
$$

где $G_{6}-$ расход циклового воздуха, $G_{2}$ - расход газов ГТУ.

Расход газов складывается из расходов циклового воздуха и топлива:

$$
G_{B}=G_{B}+B_{m}
$$

Расход топлива, подаваемого в камеру сгорания ГТУ, вычисляем с учетом его теплоты сгорания $\left(Q_{t}^{p}\right)$, мощности $\left(N_{\text {zmy }}\right)$ и КПД $\left(\eta_{\text {сmy }}\right)$ установки:

$$
-694-
$$




$$
B_{m}=\frac{N_{e m y}}{n_{2 m y} * Q_{H}^{p}} .
$$

Влияние температуры $\left(\mathrm{t}_{\text {нв }}\right)$ наружного воздуха на экономичность ГТУ проявляется зависимостью температуры $\left(\mathrm{t}_{\text {гт }}=\mathrm{t}_{4}\right)$ газов после газовой турбины от $t_{\text {нв }}$ :

$$
t_{4}^{*}=k * t_{4}
$$

где $k=1,023-\left[0,0006571 *\left(50-\mathrm{t}_{4}\right)\right]-$ коэффициент пересчета температуры газов после газовой турбины с учетом стандартной $\left(\mathrm{t}_{\text {нв }}=+15^{\circ} \mathrm{C}\right)$ и текущей температуры наружного воздуха. Расчеты проводились при постоянной температуре газов перед турбиной $=1250{ }^{\circ} \mathrm{C}$.

На рис. 2 показано влияние температуры наружного воздуха на значения термического эксергетического КПД ГТУ, которые определялись по формуле 30 (см. ниже по тексту) [5].

Для определения полноты использования эксергии топлива в цикле ГТУ необходимо определить эксергетические КПД основных элементов газотурбинной установки - турбокомпрессора, газовой турбины и камеры сгорания и потери эксергии в них. Эксергия рабочего тела (сжимаемый воздух / газы) ГТУ в каждой характерной точке газового цикла определяется по формуле

$$
e_{i}=h_{i}-h_{\mathrm{HB}}-\left[\left(t_{\mathrm{HB}}+273\right) *\left(s_{i}-s_{\mathrm{HB}}\right)\right],
$$

где $h_{i}$ и $s_{i}$ - энтальпия и энтропия рабочего тела ГТУ: $\mathrm{t}_{\mathrm{Hв}}, h_{H в}, s_{H 6}-$ температура, энтальпия и энтропия наружного воздуха.

На эксергию топлива (е ной в камеру сгорания ГТУ, относительно низшей теплоты сгорания топлива $Q_{t}^{p}$ (параметр $\mathrm{m}_{\text {тепл): }}$

$$
\begin{aligned}
& m_{\text {menл }}=\frac{q_{1}}{Q_{H}^{p} * \eta \text { Кс }}, \\
& e_{\text {monл }}=m_{\text {menл }} * Q_{H}^{p}=\frac{Q_{H}^{p} * q_{1}}{Q_{H}^{p} * \eta \mathrm{kc}}=\frac{q_{1}}{\eta_{\mathrm{kc}}} \sim q_{1} .
\end{aligned}
$$

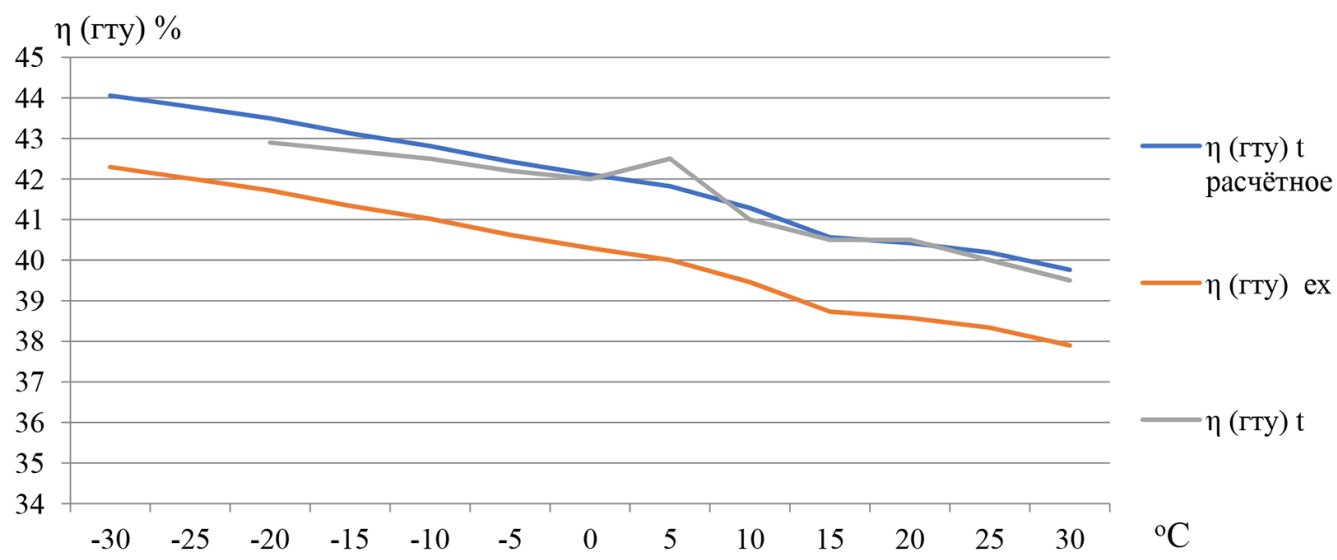

Рис. 2. Зависимость термического и эксергетического КПД ГТУ от значений $\mathrm{t}_{\text {нв }}$

Fig. 2. The dependence of thermal and exergy efficiency of gas turbines on the values $t_{\text {нв }}$ 
Потери эксергии в камере сгорания $\left(\Delta \mathrm{e}_{\text {кс }}\right)$, турбокомпрессоре $\left(\Delta \mathrm{e}_{\text {тк }}\right)$ и газовой турбине $\left(\Delta \mathrm{e}_{\text {гт }}\right)$ ГТУ, станавливают по формулам [6]:

$$
\begin{aligned}
& \Delta e_{\kappa c}=e_{\text {топл }}-\left(e_{3}-e_{2}\right), \\
& \Delta e_{m \kappa}=l_{m \kappa}-\left(e_{2}-e_{1}\right), \\
& \Delta e_{2 m}=\left(e_{2}-e_{1}\right)-l_{2 m} .
\end{aligned}
$$

Кроме того, необходимо учесть потери эксергии на трение в подшипниках и в электрическом генераторе:

$$
\Delta e_{M 2}=\left[\left(1-\eta_{M}\right) * l_{2 m}\right]+\left[\left(1-\eta_{\ni 2}\right) *\left(\left(l_{2 m} * \eta_{M}\right)-l_{m \kappa}\right)\right]
$$

где $\eta_{м}=0,985$ - механический КПД; $\eta_{э 2}=0,99-$ КПД электрогенератора.

Потери эксергии с уходящими газами ГТУ оценивают потери теплоты от газов в окружающую среду:

$$
\Delta e_{y x o d, 2}=e_{4}-e_{1}
$$

Снижение температуры наружного воздуха обусловливает возрастание указанных потерь. Эксергетические КПД основных элементов ГТУ - камеры сгорания $\left(\eta_{\kappa c}^{e x}\right)$, турбокомпрессора $\left(\eta_{m \kappa}^{e x}\right)$ и газовой турбины $\left(\eta_{z m}^{e x}\right)-$ определяют по формулам [7]:

$$
\begin{aligned}
& \eta_{\kappa c}^{e x}=1-\left(\frac{\Delta e_{\kappa c}}{\Delta e_{m o n л}}\right), \\
& \eta_{m \kappa}^{e x}=1-\left(\frac{\Delta e_{m \kappa}}{l_{m \kappa}}\right), \\
& \eta_{2 m}^{e x}=1-\left(\Delta e_{2 m} / l_{2 m}\right) .
\end{aligned}
$$

$\mathrm{C}$ понижением температуры наружного воздуха происходит увеличение потерь эксергии в камере сгорания ГТУ, в то же время потери и снижаются. Однако потери эксергии в турбокомпрессоре и в газовой турбине малы и влияют на эксергетический КПД установки в незначительной степени. Поэтому эксергетические КПД турбокомпрессора и газовой турбины ГТУ достигают высоких значений и составляют $\eta_{m \kappa}^{e x}=93,95 \ldots 94,23 \%$ и $\eta_{\text {zm }}^{e x}=94,41 \ldots 95,46 \%$.

Потери эксергии в основных элементах газотурбинной установки позволяют оценить степень совершенства газотурбинного цикла. Эксергетический КПД газотурбинной установки определяют с учетом эксергии топлива и всех составляющих потерь эксергии в газовом цикле:

$$
\eta_{\Gamma T Y}^{e x}=1-\frac{\sum \Delta e}{e_{\text {monn }}}=\frac{\Delta e_{\kappa c} * \Delta e_{m \kappa} * \Delta e_{2 m} * \Delta e_{y x o d .2} * \Delta e_{M 2}}{e_{\text {monn }}} .
$$

Таким образом, установлено, что при снижении температуры наружного воздуха суммарные потери эксергии возрастают, в то же время происходит повышение эксергии топлива, благодаря чему эксергетический КПД газотурбинной установки возрастает.

Результаты теплового и эксергетического анализов работы ГТУ GE LM6000PF приведены в табл. 1 и 2 [8].

$$
\text { - } 696-
$$




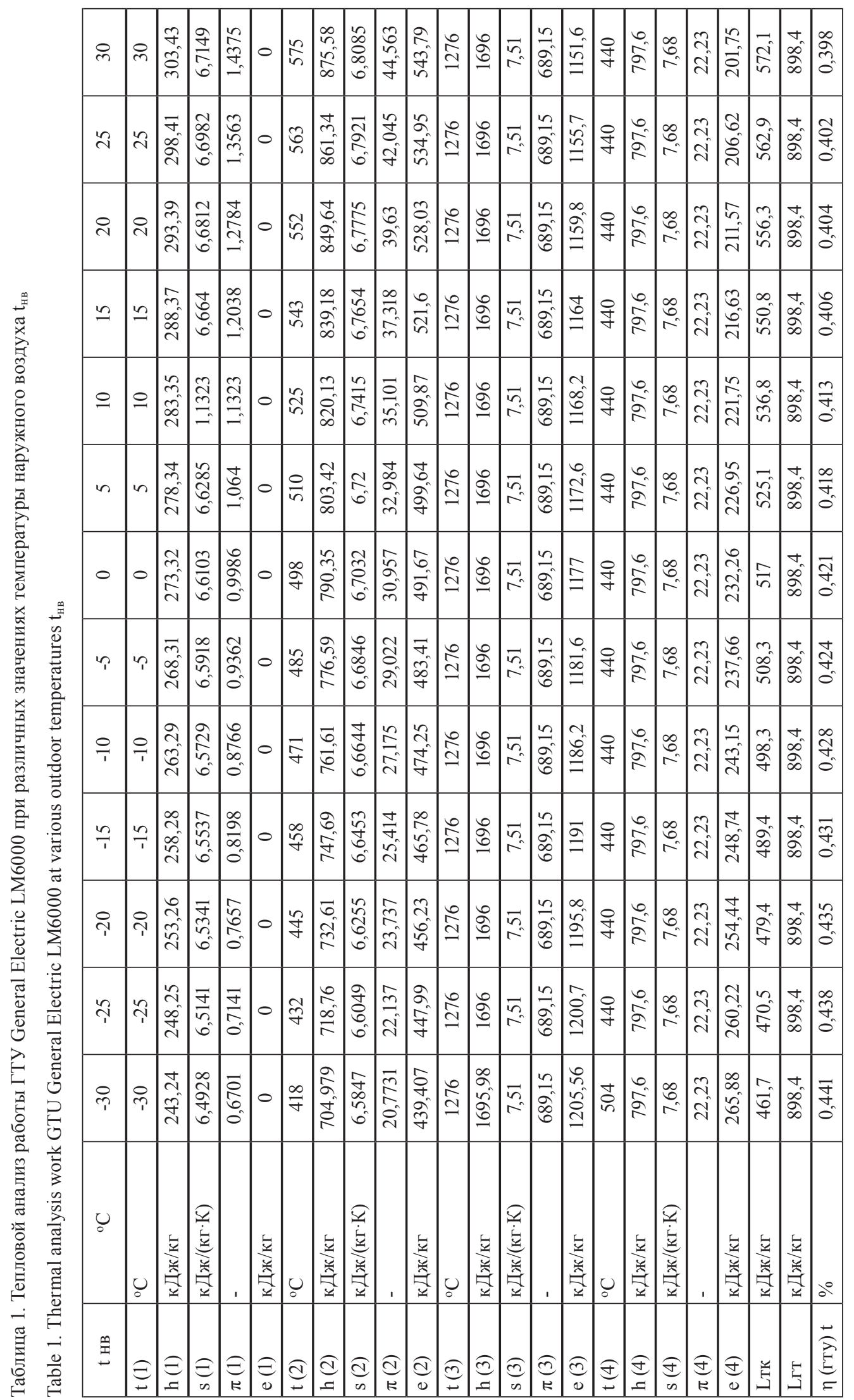




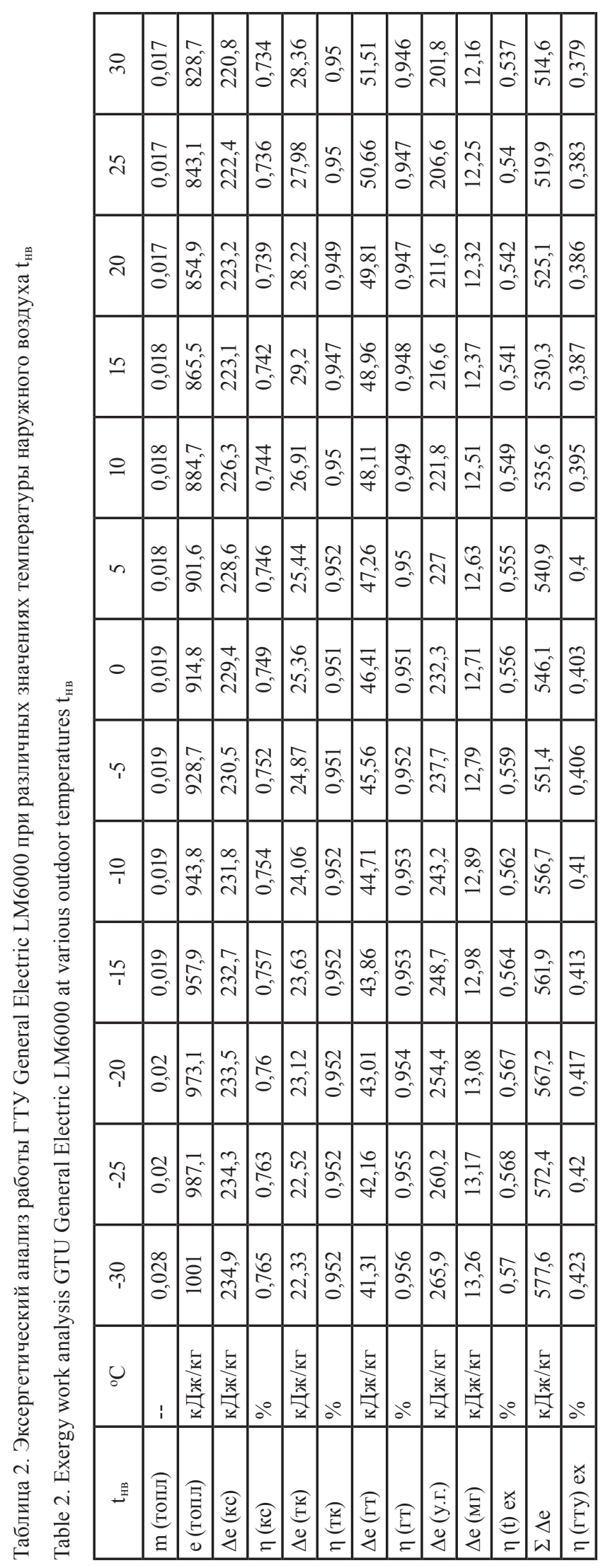




\section{Эксергетический расчет котла утилизатора}

Для определения потерь эксергии с уходящими газами ГТУ (после котла-утилизатора) необходимо определить удельное количество теплоты, подводимой к пароводяному тракту котла-утилизатора [9]:

$$
\Delta Q_{\text {вода }}=\frac{h_{1}-h_{4}}{\eta_{\text {ку }}}
$$

где $h_{1}-h_{4}-$ значения энтальпии воды на выходе и входе в котел утилизатор; $\eta_{\text {ку }}$ КПД котла утилизатора [7].

Удельный расход газов ГТУ относительно расхода сетевой воды:

$$
g=\frac{h_{1}-h_{4}}{n_{\mathrm{ky}} *\left(h_{\Gamma T}^{\prime \prime}-h_{H B}\right)},
$$

где $h_{\Gamma T}^{\prime \prime}$ - энтальпия уходящих газов газовой турбины, которая определяется по температуре $t_{\Gamma T}^{\prime \prime}$ и коэффициенту избытка воздуха а.

Эксергию уходящих газов ГТУ перед котлом-утилизатором вычисляем по формуле

$$
e_{\Gamma T}^{\prime \prime}=e_{\kappa y}^{\prime \prime}=h_{\Gamma T}^{\prime \prime}-h_{0(\mathrm{в})}-\left[\left(t_{\mathrm{HB}}+273\right) *\left(s_{\Gamma T}^{\prime \prime}-s_{0(\mathrm{в})}\right)\right] .
$$

В данной формоле $s_{\Gamma T}^{\prime \prime}$ энтропия газов после газовой турбины.

Потери эксергии с уходящими газами ГТУ характеризуют безвозвратную потерю эксергии рабочего тела ГТУ, отводимого из цикла

$$
\Delta e_{\text {газы }}=\Delta q_{\text {воды }}-e_{\Gamma T}^{\prime \prime} .
$$

Потери эксергии вследствие необратимости теплообмена между газами ГТУ и рабочим телом (вода) в котле-утилизаторе определяют по формуле

$$
\Delta e_{T / O}=e_{\Gamma T}^{\prime \prime}-\left(e_{1}-e_{4}\right),
$$

где $e_{1}$ - эксергия подогретой воды в котле-утилизаторе; $e_{4}-$ эксергия сетевой воды на входе в КУ.

Общие потери эксергии в котле-утилизаторе складываются из потерь с уходящими газами ГТУ и потерь, связанных с необратимостью процесса передачи теплоты от газов к воде:

$$
\Delta e_{\kappa y}=\Delta e_{\text {газы }}+\Delta e_{T / O}
$$

Эксергетический КПД котла-утилизатора характеризует степень полезного использования тепловой энергии газов в его водяном тракте [10]:

$$
\eta_{k y}^{e x}=1-\frac{\Delta e_{k y}}{\Delta Q_{\text {вода }}}
$$

Энтальпию газов на выходе из котла-утилизатора вычисляем по формуле

$$
h_{k y}^{\prime \prime}=h_{\Gamma T}^{\prime \prime}-\left[\left(h_{1}-h_{4}\right) / g\right] .
$$

По данной энтальпии газов и по параметрам состояния наружного воздуха $\left(t_{н \varepsilon}, h_{н в}, s_{н \varepsilon}\right)$ определяется энтропия $s_{k y}$, что позволяет расчитать эксергию газов на выходе из котла-утилизатора:

$$
\begin{gathered}
\left.\left.e_{\kappa y}^{\prime \prime}=h_{\Gamma T}^{\prime \prime}-h_{\mathrm{Hв}}-\left[\left(t_{\mathrm{HB}}+273\right) *\left(s_{\kappa y}^{\prime \prime}-s_{\mathrm{HB}}\right)\right]-h_{4}\right) / g\right] . \\
-699-
\end{gathered}
$$


Таблица 3. Эксергетический анализ работы КУВ - 46,5 - 140, работающего совместно с General Electric LM6000 при различных значениях температуры наружного воздуха $\mathrm{t}_{\text {нв }}$

Table 3. Exergy work analysis boiler - 46,5 - 140 working with General Electric LM6000 at various outdoor temperatures $\mathrm{t}_{\mathrm{HB}}[11]$

\begin{tabular}{|c|c|c|c|c|c|c|c|c|}
\hline $\mathrm{t}_{\mathrm{HB}}$ & ${ }^{\circ} \mathrm{C}$ & Минус 30 & Минус 20 & Минус 10 & 0 & 10 & 20 & 30 \\
\hline $\mathrm{h}$ нв & кДж/кг & 243,24 & 253,26 & 263,29 & 273,32 & 283,35 & 293,39 & 303,43 \\
\hline S нв & кДж/(кг·К) & 6,49 & 6,53 & 6,57 & 6,61 & 6,65 & 6,68 & 6,71 \\
\hline e $(0)$ & кДж/кг & 1104,5 & 1037,6 & 970,78 & 903,93 & 837,45 & 792,14 & 708,15 \\
\hline e (4) & кДж/кг & 132,64 & 128,63 & 124,62 & 120,62 & 116,98 & 134,5 & 113,35 \\
\hline е (4) д & кДж/кг & 174,59 & 170,48 & 166,38 & 162,27 & 158,53 & 175,96 & 154,71 \\
\hline e (" гт) & кДж/кг & 1651,8 & 1607,2 & 1566,1 & 1528,7 & 1495,2 & 1445,7 & 1398,4 \\
\hline$\Delta \mathrm{e}(\mathrm{c} \Gamma)$ & кДж/кг & 1805,2 & 1849,8 & 1890,9 & 1928,3 & 1961,8 & 2011,3 & 2058,6 \\
\hline$\Delta \mathrm{e}$ (теп) & кДж/кг & 1004,2 & 959,64 & 918,53 & 881,12 & 847,64 & 798,17 & 750,88 \\
\hline$\Delta \mathrm{e}(к у)$ & кДж/кг & 2809,4 & 2809,4 & 2809,4 & 2809,4 & 2809,4 & 2809,4 & 2809,4 \\
\hline КПД КУ & $\%$ & 0,1873 & 0,1873 & 0,1873 & 0,1873 & 0,1873 & 0,1873 & 0,1873 \\
\hline h (у.г.) & кДж/кг & 440,11 & 447,22 & 454,35 & 461,47 & 468,59 & 475,72 & 482,85 \\
\hline e (у.г.) & кДж/кг & 530,26 & 556,27 & 583,25 & 611,27 & 640,37 & 651,89 & 654,32 \\
\hline
\end{tabular}

Результаты эксергетического анализа работы КУ совместно GE LM6000PF приведены в табл. 3 [8].

\section{Заключение}

Эксергетический метод оценки энергоэффективности ГТУ позволяет более детально оценить потери ГТУ. Эксергетический анализ дает возможность выявить наиболее слабые элементы теплосиловой установки с позиций энергоэффективности и определить меры и конструкторские решения по повышению их термодинамического совершенства. Эксергетический анализ учитывает потери от неравновесности процессов в термодинамической системе при заданных условиях окружающей среды. Поэтому он позволяет проводить как относительную (определение эксергетического КПД), так и абсолютную (определение теплового КПД) степень термодинамического совершенства оборудования по сравнению с анализом, основанным на энергетическом. Таким образом, эксергетический анализ дополняет энергетический анализ, который основан на составлении балансов энергии. Достоинством эксергетического анализа является возможность оценивать степень совершенства процессов передачи и полезного использования энергии путем сравнения разности эксергии на входе и выходе элемента установки (турбокомпрессор, газовая турбина, камера сгорания, котел-утилизатор, паровая турбина и др.). К примеру, при оценке эффективности работы ГТУ и котла-утилизатора эксергетическим методом учитывается организация процессов использования химической энергии сжигаемого в камере сгорания ГТУ топлива и передачи теплоты воде, в то время как при энергетическом (тепловом) анализе котел-утилизатор рассматривается в качестве простого теплообменника.

\section{Список литературы}

[1] Ипатов В.Б. Эксергетический анализ технико-экономических показателей тепловой электростанции: Технический отчет / Дальтехэнерго; Владивосток, 1994 - 57 c. [Ipatov V.B. 
Exergetic analysis of technical and economic indicators of a thermal power plant: Technical report / Daltehenergo; Vladivostok (rus)].

[2] Штым А.Н., Ипатов В.Б. Эксергетический анализ основного оборудования ТЭС // Тез. докл. НТК ДВГТУ «Вологдинские чтения», 24-27 ноябрь 1998 г. Владивосток, 1998. С. 36. [Shtym A.N., Ipatov V.B. Exergetic analysis of the main equipment of TPP/ Abstract report NTK $D V G T U$ «Vologdinskiy's reading» (rus)]

[3] Минэнерго России. Приказ от 30.12.2008 № 323 (ред. от 30.11.2015) Об утверждении порядка определения нормативов удельного расхода топлива при производстве электрической и тепловой энергии [Электронный ресурс] - Режим доступа: http://docs.cntd.ru/ document/902148460 - [Ministry of Energy of Russia. Order dated 30.12.2008 No. 323 (as revised from 30.11.2015) On approval of the procedure for determining the standards for specific fuel consumption in the production of electrical and thermal energy [Electronic resourse] - Access: http://docs.cntd.ru/ document/902148460 (rus)]

[4] Александров А.А. Термодинамические основы циклов теплоэнергетических установок. М.: Издательский дом МЭИ, 2004. 158 с. [Aleksandrov A.A. Thermodynamic foundations of cycles of thermal power plants, Publishing House MEI, 2004, 158 p. (rus)]

[5] Александров А.А., Григорьев Б.А. Таблицы теплофизических свойств воды и водяного пара. М.: Издательский дом МЭИ, 2006. 164 с. [Aleksandrov A.A , Grigoryev B.A. Tables of thermophysical properties of water and steam, Publishing House MEI 2006, 164 p. (rus)]

[6] Андрющенко А.И., Ларин Е.А., Сандалова Л.А. Метод эксергетического анализа термодинамических систем и комплексов. Саратовский государственный технический университет, 2008. 74 с. [Andryshenko A.I., Larin E.A., Sandalova L.A. The method of exergy analysis of thermodynamic systems and complexes. SSTU, 2008, 74 p. (rus)]

[7] Андрющенко А.И., Аминов Р.3. Оптимизация режимов работы и параметров тепловых электростанций. М.: Высшая школа, 1983. 255 с. [Andryshenko A.I., Aminov R.Z. Optimization of operating modes and parameters of thermal power plants, Hight school, 1983, 255 p. (rus)]

[8] Андрющенко, А.И., Николаев Ю.Е. Экологическая и экономическая эффективность замены устаревшего паротурбинного оборудования ТЭЦ на газотурбинное и парогазовое. Промышленная энергетика. 2006, № 7, с. 2-6 [Andryshenko A.I., Nikolaev U.E. Environmental and economic efficiency of replacing obsolete steam turbine equipment of CHP plants with gas turbine and combined cycle equipment. Industrial energy, 2006, 7, 2-6. (rus)]

[9] Арсеньев Л.В., Тырышкин В.Г. Комбинированные установки с газовыми турбинами. Л.: Машиностроение, 1982. 247 c. [Arsenyev L.V., Tyryshkin V.G. Combined units with gas turbines. Mechanical engineering, 1982, 247 p. (rus)]

[10] Байгалиев Б.Е., Щелчков А.В., Яковлев А.Б., Гортышов П.Ю. Теплообменные аппараты. Казанский государственный энергетический университет, 2012, 180 с. [Baygaliev B.E., Chelchkov A.B., Yakovlev A.B., Gortyshov P.U. Heat exchangers. KSEU, 2012, 180 p. (rus)]

[11] Барочкин Е.В., Жуков В.П., Борисов А.А., Ледуховский Г.В. Повышение эффективности работы ТЭЦ на основе оптимизации распределения сетевой воды. Энергетик. №10. 2012. C. 13-15. [Barochkin E.V., Zhukov V.P., Borisov A.A., Leduhovskiy G.V. Improving the efficiency of the CHP plant based on the optimization of the distribution of network water. Energetik №10, 2012, p. 13-15 (rus)] 